\title{
Efeito da hiperprolactinemia induzida pela metoclopramida na glândula lacrimal: estudo experimental
}

\author{
Effects of metoclopramide-induced hyperprolactinemia on the lacrimal gland: experimental study
}

\author{
Carina Verna ${ }^{1}$, Fernanda Watanabe Martins ${ }^{2}$, Rejane Mosquette ${ }^{3}$, Ricardo Santos Simões ${ }^{4}$, \\ Manuel de Jesus Simões ${ }^{5}$, José Maria Soares Júnior ${ }^{6}$, Edmund Chada Baracat ${ }^{7}$
}

\section{RESUMO}

Objetivo: avaliar as alterações morfológicas promovidas pela hiperprolactinemia induzida pela metoclopramida na glândula lacrimal de camundongas durante a fase de proestro e gestação. Métodos: 40 camundongas adultas foram divididas em dois grupos: CTR1 (controle) e MET1 (tratadas com metoclopramida). Após 50 dias, metade dos animais de cada grupo foram sacrificados por decapitação. Os restantes foram acasalados, constituindo os grupos controle prenhe (CTR2) e metoclopramida prenhe (MET2), que foram sacrificadas no $6^{\circ}$ dia de gestação. O sangue foi coletado e submetido à dosagem hormonal dos níveis de estradiol e de progesterona por quimioluminescência. Em seguida as glândulas lacrimais foram removidas, fixadas em formol a $10 \%$ e processadas segundo metodologia histológica para inclusão em parafina, sendo as lâminas coradas pelo HE. A análise morfométrica foi realizada com o programa AxionVision (Carl Zeiss), medindo-se os volumes celulares e nucleares das células acinares. Resultados: os volumes nuclear e celular das glândulas lacrimais dos grupos experimentais MET1 $\left(152,2 \pm 8,7 ; 6,3 \pm 1,6 \mu \mathrm{m}^{3}\right)$ e MET2 $\left(278,3 \pm 7,9 ; 27,5 \pm 0,9 \mu \mathrm{m}^{3}\right)$ mostraram-se reduzidos em relação aos grupos controles CTR1 $\left(204,2 \pm 7,4 ; 21,9 \pm 1,3 \mu \mathrm{m}^{3}\right)$ e CTR2 $\left(329,4 \pm 2,2 ; 35,5 \pm 2,0 \mu \mathrm{m}^{3}\right)$. Houve redução dos níveis hormonais de estrogênio e de progesterona nos animais que receberam metoclopramida em comparação com os respectivos controles $(C T R 1$ : estradiol $=156,6 \pm 42,2 \mathrm{pg} / \mathrm{mL} ;$ progesterona $=39,4 \pm 5,1 \mathrm{ng} / \mathrm{mL} ;$ MET1: estradiol $=108,0 \pm 33,1 \mathrm{pg} / \mathrm{mL} ;$ progesterona $=$ $28,0 \pm 6,4 \mathrm{ng} / \mathrm{mL}$; CTR2: estradiol $=354,0 \pm 56,0 \mathrm{pg} / \mathrm{mL}$; progesterona $=251,0 \pm 56,0 \mathrm{ng} / \mathrm{mL}$; MET2: estradiol $=293,0 \pm 43,0 \mathrm{pg} / \mathrm{mL}$, progesterona $=184,0 \pm 33,0 \mathrm{ng} / \mathrm{mL}$ ). Conclusão: a hiperprolactinemia induzida pela metoclopramida produziu sinais de diminuição na atividade das células da glândula lacrimal tanto em camundongas prenhes quanto não prenhes. Este efeito está possivelmente relacionado com a redução da produção hormonal de estrogênio e progesterona.

PALAVRAS-CHAVE: Hiperprolactinemia/induzido quimicamente; Metoclopramida; Glândula lacrimal/efeito de drogas; Camundongos

\section{ABSTRACT}

Purpose: to evaluate the morphological changes in murine lacrimal glands by metoclopramide-induced hyperprolactinemia during the proestrus phase or pregnancy. Methods: forty adult mice were divided into two groups: CTR1 (control) and MET1 (treated with metoclopramide). After fifty days, half of the mice were sacrificed. The remaining animals were mated, and then labeled as pregnant controls (CTR2). Part of these animals were treated with metoclopramide and constituted the metoclopramide-treated pregnant (MET2) group. The CTR2 and MET2 groups were sacrificed on the 6th day of pregnancy. The blood was collected for determination of the hormonal levels of estradiol and progesterone by a chemoluminescent method. The lacrimal glands were then removed, fixed in $10 \%$ formaldehyde and stained with HE. The morphometric analysis was performed using the Axion Vision program (Carl Zeiss) to measure acinar nuclear and cellular volumes. Results: the nuclear and cellular volumes of the lacrimal glands in the MET1-(152.2 $\left.\pm 8.7 ; 6.3 \pm 1.6 \mu \mathrm{m}^{3}\right)$ and MET2-(278.3 $\left.\pm 7.9 ; 27.5 \pm 0.9 \mu \mathrm{m}^{3}\right)$ treated groups were lower than those in CTR1 $\left(204.2 \pm 7.4 ; 21.9 \pm 1.3 \mu \mathrm{m}^{3}\right)$ and CTR2 $\left(329.4 \pm 2.2 ; 35.5 \pm 2.0 \mu \mathrm{m}^{3}\right)$, respectively. There was a significant hormonal level reduction in the animals that received metoclopramide compared to controls (CTR1:

\footnotetext{
Departamentos de Ginecologia e Morfologia da Universidade Federal de São Paulo - UNIFESP - São Paulo (SP) - Brasil.

1 Pós-Graduanda do Departamento de Ginecologia da Universidade Federal de São Paulo - UNIFESP - São Paulo (SP) - Brasil.

2 Tecnóloga Oftálmica da Universidade Federal de São Paulo - UNIFESP - São Paulo (SP) - Brasil.

3 Pós-Graduanda do Departamento de Morfologia da Universidade Federal de São Paulo - UNIFESP - São Paulo (SP) - Brasil.

4 Residente de Ginecologia e Obstetrícia da Universidade Federal de São Paulo - UNIFESP - São Paulo (SP) - Brasil.

5 Professor Associado da Disciplina de Histologia da Universidade Federal de São Paulo - UNIFESP - São Paulo (SP) - Brasil.

6 Professor Doutor do Departamento de Ginecologia da Universidade Federal de São Paulo - UNIFESP - São Paulo (SP) - Brasil.

7 Professor Titular do Departamento de Ginecologia da Universidade Federal de São Paulo - UNIFESP - São Paulo (SP) - Brasil.

Apoio financeiro: FAPESP (Proc. $\mathrm{n}^{\circ}$ 04/01746-7)

Correspondência: José Maria Soares Júnior

Avenida Sena Madureira 1245, apto 11 - Vila Clementino - 04021-051 - São Paulo - SP - Tel/Fax: 11-5081-3685
} 
estradiol $=156.6 \pm 42.2 \mathrm{pg} / \mathrm{mL} ;$ progesterone $=39.4 \pm 5.1 \mathrm{ng} / \mathrm{mL} ;$ MET1: estradiol $=108.0 \pm 33.1 \mathrm{pg} / \mathrm{mL} ;$ progesterone $=28.0 \pm 6.4$ $\mathrm{ng} / \mathrm{mL}$; CTR2: estradiol $=354.0 \pm 56.0 \mathrm{pg} / \mathrm{mL} ;$ progesterone $=251.0 \pm 56.0 \mathrm{ng} / \mathrm{mL} ;$ MET2: estradiol $=293.0 \pm 43.0 \mathrm{pg} / \mathrm{mL}$, progesterone $=184.0 \pm 33.0 \mathrm{ng} / \mathrm{mL}$ ). Conclusion: metoclopramide-induced hyperprolactinemia produced morphological signs of reduction of cellular activity in lacrimal glands during the proestrus phase and pregnancy. It is hypothesized that this effect might be related to the hyperprolactinemia-induced decrease in the hormonal production of estrogen and progesterone.

KEYWORDS: Hyperprolactinemia/chemically induced; Metoclopramide; Lacrimal gland/drug effects; Mice

\section{Introdução}

O declínio da função da glândula lacrimal constitui a maior causa de instabilidade do filme lacrimal e a principal etiologia do olho seco, que é queixa freqüente em mulheres na transição menopausal e pós-menopausal com níveis elevados de prolactina ${ }^{1}$.

Além da participação da prolactina, pode haver ainda um fator imunológico adicional, como a redução da secreção de imunoglobulinas, principalmente de IgA no filme lacrimal ${ }^{2}$. A reforçar esta hipótese, estudos experimentais sugerem que os estrogênios participariam da produção do filme lacrimal. A redução dos níveis plasmáticos de estradiol aumentaria a taxa de apoptose do tecido glandular, levando à diminuição do volume das glândulas ${ }^{3}$. Assim, a causa primária da deficiência de lágrimas estaria relacionada com alterações endócrinas, muito possivelmente relacionadas aos esteróides ovarianos e com a participação de hormônios hipofisários, como a prolactina ${ }^{2}$.

As glândulas lacrimais estão localizadas na borda súpero-externa da órbita; são glândulas serosas do tipo túbulo-alveolar. Desembocam, por meio de oito a dez canais, no fundo de saco superior, que é formado pela confluência da conjuntiva que reveste o olho com a que cobre posteriormente a pálpebra. São constituídas por células com grânulos de secreção que têm fraca reação pela técnica de imuno-histoquímica. A sua porção secretora acha-se envolvida por células mioepiteliais. Produzem secreção salina cuja concentração de cloreto de sódio é similar à do sangue. É um fluido pobre em proteínas, que contém uma única enzima, a lisozima, que digere a cápsula de algumas bactérias ${ }^{4}$.

A prolactina é hormônio polipeptídico secretado pela hipófise. É constituída por uma cadeia de 198 aminoácidos, com peso molecular de 23 kilodaltons ${ }^{5}$. No passado, era conhecida apenas por controlar a secreção láctea, mas, atualmente, tem ação sistêmica reconhecida, incluindo seu efeito na reprodução tanto do ser humano quanto de outros mamíferos ${ }^{1}$. A descoberta da prolactina em animais data de 1928, quando foram descritas suas propriedades somatotróficas. No entanto, a detecção na espécie humana só foi possivel após o advento da técnica de radioimunoensaio ${ }^{5}$.

A prolactina atua de modo sinérgico com a progesterona e o estrogênio na promoção do crescimento e do funcionamento das glândulas mamárias e outros tecidos-alvo ${ }^{5}$. Está também envolvida com o equilíbrio hídrico, bem como no crescimento e diferenciação celular, regulação da sintese de proteínas e regulação de respostas imunológicas ${ }^{6,7}$.

$\mathrm{Na}$ área experimental, a metoclopramida tem sido bastante utilizada em animais, com o propósito de elevar os níveis séricos de prolactina e estudar seus efeitos sobre os tecidos-alvo ${ }^{8}$, por atuar diretamente sobre a hipófise, aumentando a sintese de prolactina ${ }^{9}$.

Assim, o presente trabalho tem como objetivo avaliar a histomorfologia e histomorfometria das glândulas lacrimais de camundongas durante a fase de proestro (pico hormonal de esteróides sexuais) e a gestação (elevação de progesterona), periodos em que a função glandular está aumentada. Tem também o objetivo de analisar o efeito da hiperprolactinemia nestas estruturas, as quais são responsáveis pela produção do filme lacrimal.

\section{Métodos}

\section{Animais e tratamentos}

Foram utilizadas 40 camundongas (Mus musculus) adultas, com 3 meses de idade, virgens, procedentes do Centro de Desenvolvimento de Modelos de Experimentação (CEDEME) da Universidade Federal de São Paulo. Os animais foram mantidos, em número de 10 por gaiola, com alimentação e água ad libitum, em temperatura ambiente de $22^{\circ} \mathrm{C}$ e iluminação artificial com lâmpadas fluorescentes marca Phillips (modelo luz do dia de $40 \mathrm{~W})$. Foram mantidos em fotoperiodo claro de 12 horas intercalado com período escuro de 12 horas, sendo o periodo de luz das 6:00 às 18:00 horas. Este projeto foi aprovado pelo Comitê de Ética e Pesquisas da Universidade Federal de São Paulo - Escola Paulista de Medicina (UNIFESP-EPM).

Os animais foram divididos, ao acaso, inicialmente em dois grupos: controle não-prenhe (CTR1) - composto de 20 camundongas que receberam injeções diárias, por via subcutânea, de 0,2 mL de 
solução salina a 0,9\%, e metoclopramida não-prenhe (MET1) - constituído de 20 camundongas que receberam injeções diárias, por via subcutânea, de $200 \mu \mathrm{g}$ de metoclopramida, dissolvidos em $0,2 \mathrm{~mL}$ de solução salina a $0,9 \%$. A dose e a duração de tratamento com metoclopramida, que induz hiperprolactinemia, foi determinada em outro experimento realizado em nosso laboratório ${ }^{8}$.

Todos os animais receberam solução salina ou metoclopramida durante 50 dias consecutivos, sempre às 18:00 horas. Após a administração do fármaco ou da solução físiológica, colhia-se material para avaliar o ciclo estral. No $50^{\circ}$ dia, logo após a administração das soluções, os animais de ambos os grupos que se encontravam na fase de proestro foram sacrificados. Os animais restantes foram então colocados para acasalamento, na proporção de três fêmeas para cada macho, sabidamente reprodutor.

O coito foi comprovado pela presença de tampão de espermatozóides na vagina. Em alguns animais, que apresentavam dilatação do orificio externo da vagina, foi realizada coleta do material presente no seu interior para identificação de espermatozóides em microscopia de luz. Metade dos animais prenhes não foi tratada, constituindo o grupo controle prenhe (CRT2), e a outra metade foi medicada com metoclopramida, como descrito anteriormente, constituindo então o grupo metoclopramida prenhe (MET2). Os animais destes dois grupos foram sacrificados no $6^{\circ}$ dia de prenhez.

Imediatamente após a decapitação dos animais, coletou-se sangue para determinação dos niveis plasmáticos de estrogênio e de progesterona por radioimunoensaio. A seguir, foram retiradas as glândulas lacrimais para processamento histológico e estudo em microscopia de luz. Para tanto, primeiramente, as glândulas foram mergulhadas em formol a 10\% tamponado e na seqüência processadas para inclusão em parafina. Os blocos foram cortados em micrótomo do tipo Minot, ajustado para $3 \mu \mathrm{m}$. Para cada glândula foram realizados 5 cortes, com espaçamento de $0,5 \mathrm{~cm}$, de tal maneira que toda a glândula foi cortada. Os cortes obtidos foram então submetidos ao método de coloração pela hematoxilina e eosina (HE).

\section{Análise morfométrica}

A avaliação histológica e morfométrica foi realizada por sistema de captura de imagens, as quais foram analisadas pelo programa AxionVision (Zeiss). Este processo consiste de um microscópio de luz (Axiolab Standart 20, Zeiss), acoplado a uma vídeocâmera de alta resolução (AxionCam - Zeiss), que transmite a imagem a um computador.

Para cada animal, foram obtidas imagens de 20 células acinares em cada corte, perfazendo um total de 100 células por animal. Foram analisados o volume celular e o nuclear das células acinares.

No sangue obtido foram dosados, por imunoensaio enzimático quimioluminescente competitivo em fase sólida, os niveis de estradiol e de progesterona (Immulite ${ }^{\circledR}$, USA), com sensibilidade de $15 \mathrm{pg} / \mathrm{mL}$ e $0,2 \mathrm{ng} / \mathrm{mL}$ respectivamente para o estradiol e a progesterona, com alta especificidade para estes hormônios.

\section{Análise estatistica}

Os resultados foram apresentados como média e erro padrão da média (EPM). Na comparação entre os grupos, foram analisados separadamente os animais não prenhes (CTR1 e MET1) dos prenhes (CTR2 e MET2). Após análise de variação pelo programa Prizma ${ }^{\circledR}$ (Califórnia, Estados Unidos da América), aplicou-se o teste $t$ de Student não pareado, comparando-se o CTR1 com o MET1 e o CTR2 com o MET2 para os dados morfométricos e dosagem hormonal (estrogênio e progesterona). Adotou-se o nivel de significância (alfa) de 0,05.

\section{Resultados}

\section{Morfológicos}

Grupo controle não-prenhe (CTR1): notaramse glândulas lacrimais contendo ácinos, revestidos por células prismáticas, com lúmen bem evidente. Entre os ácinos observou-se a presença de ductos, revestidos por células cilíndricas. As células acinares apresentavam núcleos volumosos, esféricos, deslocados para a porção basal e ricos em eucromatina. Na porção apical destas células, havia áreas eosinófilas, sugestivas da presença de secreção em seu interior (Figura 1A).

Grupo metoclopramida não prenhe (MET1): neste grupo, as glândulas lacrimais estavam formadas por ácinos e ductos. Os ácinos achavam-se revestidos por células cúbicas, de menor tamanho, comparativamente ao grupo controle. Os núcleos eram esféricos, ricos em heterocromatina; no citoplasma notou-se redução da área eosinofilica. Deve-se ressaltar que os ductos eram parecidos aos do grupo controle (Figura 1B).

Grupo controle prenhe (CTR2): os ácinos das glândulas lacrimais eram semelhantes aos do grupo controle não prenhe; no entanto, as células acinares eram mais volumosas e apresentavam maior área (Figura 1C).

Grupo metoclopramida prenhe (MET2): de igual modo, os ácinos lacrimais eram parecidos com os do grupo prenhe controle (CTR2), contudo, as células eram menores (Figura 1D). Os ductos lacrimais mostravam-se nos vários grupos de estudo. 

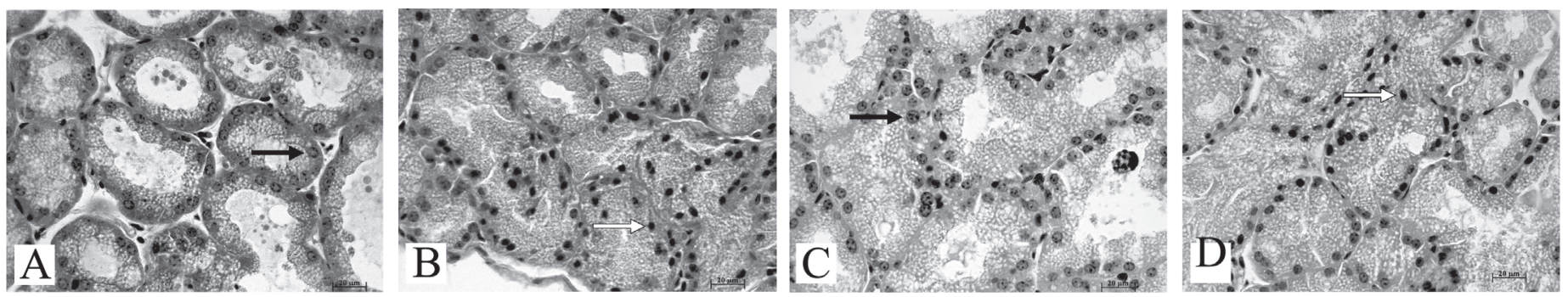

Figura 1 - Fotomicrografias mostrando parte de corte da glândula lacrimal de camundonga pertencente ao grupo CTR1 (A), MET1 (B), CTR2 (C) e MET2 (D). Observar em A e em C ácinos contendo núcleos volumosos com cromatina descondensada (eucromatina) (setas pretas) e em B e D núcleos contendo cromatina bem condensada (heterocromatina) (setas brancas). HE x aumento.

\section{Morfométricos}

As médias e os erros-padrão da média dos volumes celular e nuclear das células acinares das glândulas lacrimais dos grupos não prenhe (MET1) e prenhe (MET2) que receberam metoclopramida mostraram-se significativamente menores em relação aos respectivos grupos controle, tanto não prenhe (CTR1) como prenhe (CTR2), que não receberam metoclopramida. Os valores do volume celular foram: $204,2 \pm 7,4 ; 152,2 \pm 8,7$; $329,4 \pm 2,2$, e $278,3 \pm 7,9 \mu \mathrm{m}^{3}$, respectivamente, para os grupos CTR1, MET1, CTR2 e MET2. Já os valores obtidos do volume nuclear foram: 21,9 $\pm 1,3$; $6,3 \pm 1,6 ; 35,5 \pm 2,0$ e $27,5 \pm 0,9 \mu \mathrm{m}^{3}$, respectivamente, para os grupos CTR1, MET1, CTR2 e MET2 (Tabela 1$)$.

Tabela 1 - Efeitos do tratamento com metoclopramida sobre os volumes celular e nuclear das glândulas lacrimais e das dosagens hormonais em camundongas prenhes e não prenhes.

\begin{tabular}{|c|c|c|c|c|c|c|}
\hline Estadofisiológico & Tratamento & Grupo & Vol. celular $\left(\mu \mathrm{m}^{3}\right)$ & Vol. nuclear $\left(\mu \mathrm{m}^{3}\right)$ & Estradiol $(\mathrm{pg} / \mathrm{mL})$ & Progesterona $(\mathrm{ng} / \mathrm{mL})$ \\
\hline \multirow[t]{2}{*}{ Não-prenhe } & Solução salina & CTR1 & $204,2 \pm 7,4$ & $21,9 \pm 1,3$ & $156,6 \pm 42,2$ & $39,4 \pm 5,1$ \\
\hline & Metoclopramida & MET1 & $152,2 \pm 8,7^{\mathrm{a}}$ & $6,3 \pm 1,6^{a}$ & $108,0 \pm 33,1^{a}$ & $28,0 \pm 6,4^{\mathrm{a}}$ \\
\hline \multirow[t]{2}{*}{ Prenhe } & Solução salina & CTR2 & $329,4 \pm 2,2$ & $35,5 \pm 2,0$ & $354,0 \pm 56,0$ & $251,0 \pm 56,0$ \\
\hline & Metoclopramida & MET2 & $278,3 \pm 7,9^{b}$ & $27,5 \pm 0,9^{b}$ & $293,0 \pm 43,0^{b}$ & $184,0 \pm 33,0^{b}$ \\
\hline
\end{tabular}

Os valores representam média \pm EPM (erro padrão da média). Cada grupo consistiu de 10 animais. ap $<0,05$ em comparação com os respectivos valores dos grupos tratados com metoclopramida nos animais não prenhes; ${ }^{b} p<0,05$ em comparação com os respectivos valores dos grupos prenhes.

\section{Dosagens de estradiol e progesterona}

Os valores séricos nos diferentes grupos foram: CTR1: estradiol $=156,6 \pm 42,2 \mathrm{pg} / \mathrm{mL}$; progesterona $=39,4 \pm 5,1 \mathrm{ng} / \mathrm{mL} ;$ MET 1 : estradiol $=$ $108,0 \pm 33,1 \mathrm{pg} / \mathrm{mL}$; progesterona $=28,0 \pm 6,4 \mathrm{ng} / \mathrm{mL}$; CTR2: estradiol $=354,0 \pm 56,0 \mathrm{pg} / \mathrm{mL}$; progesterona $=251,0 \pm 56,0 \mathrm{ng} / \mathrm{mL} ;$ MET2: estradiol = $293,0 \pm 43,0 \mathrm{pg} / \mathrm{mL}$, progesterona $=184,0 \pm 33,0 \mathrm{ng} /$ $\mathrm{mL}$. As médias dos niveis de estrogênio e progesterona foram mais elevadas nos grupos prenhes (CTR2 e MET2) em comparação aos não-prenhes (CTR1 e MET1) ( $\mathrm{p}<0.05)$. Quando se compararam os grupos com e sem metoclopramida, detectouse redução significante nos níveis séricos dos valores desses hormônios nos grupos não prenhe (MET1) e prenhe (MET2) que receberam metoclopramida, em relação aos grupos não prenhe (CTR1) e prenhe (CTR2) que receberam apenas veículo, $(\mathrm{p}<0,05)$ (Tabela 1).

\section{Discussão}

A prolactina está presente no filme lacrimal de humanos, e poderia atuar nas células acinares da glândula lacrimal ${ }^{9}$. Em estudos em glândulas lacrimais de ratos se confirmou a presença de re- ceptores para prolactina nas células acinares e também se identificou RNA mensageiro de prolactina no extrato das glândulas lacrimais. Estes dados sugerem que a prolactina poderia interferir na função da glândula lacrimal ${ }^{11}$. Neste particular, os nossos dados mostraram que houve, na vigência de hiperprolactinemia induzida pela metoclopramida, alteração morfométrica das células da glândula lacrimal.

Os receptores para prolactina já foram detectados na glândula lacrimal e se demonstrou que este hormônio poderia ter um papel modulador sobre a função destas glândulas ${ }^{10}$. Sabe-se que as concentrações dos dois tipos de receptores da prolactina, o de cadeia curta (PRLR) e o de cadeia longa (PRLPR), estão na dependência dos níveis séricos dos hormônios sexuais ${ }^{11}$.

Em camundongos, a hipofisectomia pode promover alteração no lacrimejamento e, em contrapartida, o reimplante hipofisário restaura o volume da produção de lagrimas ${ }^{13}$. O hormônio hipofisário responsável por esta ação ainda não está estabelecido, mas dados experimentais indicam que a prolactina teria efeito no trofismo da glândula lacrimal, nesses animais ${ }^{12}$. Além disso, a hiperprolactinemia em camundongas levaria a menor produção do filme lacrimal e, assim, participaria da sindrome do olho seco ${ }^{13}$. 
Em animais transgênicos que têm baixa produção de prolactina e defeito no receptor de prolactina (PRLR-1), foi demonstrado que a prolactina é importante na secreção lacrimal ${ }^{14}$.

Durante a gestação em hamsters, há aumento da função da glândula lacrimal e no pico hormonal do ciclo estral registra-se maior produção de porfirinas ${ }^{15}$. Estudos com microscopia eletrônica de transmissão revelaram que, em camundongas prenhes, há redução da produção de progesterona e a taxa de implantação é significativamente menor em comparação aos controles, provavelmente devido ao menor número de pinopódios, ou seja, microvilosidades das células epiteliais do endométrio que facilitam a fixação do blastocisto no epitélio luminal ${ }^{15}$. Além disso, em coelhas, há maior secreção da glândula lacrimal durante a gestação e queda durante a lactação ${ }^{16}$.

A hiperprolactinemia experimental induzida pela metoclopramida em camundongas ${ }^{9}$ reduz a sintese de esteróides ovarianos durante a fase de proestro e também a de progesterona na gestação. Em conseqüência, o efeito da elevação da prolactinemia sobre a função da glândula lacrimal pode estar associado com a diminuição da ação da progesterona.

Deve-se ressaltar que pacientes com sindrome de Sjögren têm ressecamento ocular e apresentam niveis elevados de prolactina ${ }^{17}$. Contudo, a relação da hiperprolactinemia com a sindrome do olho seco ainda não está bem definida. Nossos resultados mostraram que houve sinais histológicos de diminuição da atividade celular das glândulas lacrimais de camundongas. Este efeito pode ser direto pela ação da prolactina nesse tecido ou pela redução dos hormônios sexuais (estrogênio e progesterona). Esses achados sugerem que esta alteração glandular pode ter, entre outros, importante componente endócrino em sua gênese.

\section{Conflitos de interesse}

Não existem conflitos de interesse

\section{Referências}

1. Mathers WD, Stovall D, Lane JA, Zimmerman MB, Johnson S. Menopause and tear function: the influence of prolactin and sex hormones on human tear production. Cornea. 1998;17(4):353-8.

2. Warren DW. Hormonal influences on the lacrimal gland. Int Ophthalmol Clin. 1994;34(1):19-25.

3. Ishimaru N, Saegusa K, Yanagi K, Haneji N, Saito I, Hayashi Y. Estrogen deficiency accelerates autoimmune exocrinopathy in murine Sjogren's syndrome through fas-mediated apoptosis. Am J Pathol. 1999;155(1):173-81.

4. Pinard CL, Weiss ML, Brightman AH, Fenwick BW, Davidson HJ. Evaluation of lysozyme and lactoferrin in lacrimal and other ocular glands of bison and cattle and in tears of bison. Am J Vet Res. 2003;64(1):104-8.

5. Lewis UJ, Singh RN, Seavey BK. Human prolactin: isolation and some properties. Biochem Biophys Res Commun. 1971;44(5):1169-76.

6. Brand JM, Frohn C, Cziupka K, Brockmann C, Kirchner H, Luhm J. Prolactin triggers proinflammatory immune responses in peripheral immune cells. Eur Cytokine Netw. 2004;15(2):99-104.

7. Carreno PC, Sacedon R, Jimenez E, Vicente A, Zapata AG. Prolactin affects both survival and differentiation of T-cell progenitors. J Neuroimmunol. 2005;160(12):135-45.

8. Rossi AG, Soares JM Jr, Motta EL, Simoes MJ, OliveiraFilho RM, Haidar MA, et al. Metoclopramide-induced hyperprolactinemia affects mouse endometrial morphology. Gynecol Obstet Invest. 2002;54(4):185-90.

9. Betzold CM. Galactagogues. J Midwifery Womens Health. 2004;49(2):151-4.

10. Oprea L, Tiberghien A, Creuzot-Garcher C, Baudouin C. Hormonal regulatory influence in tear film. J Fr Ophtalmol. 2004;27(8):933-41.

11. Kinoshita H, Yasui T, Ushigoe K, Irahara M, Tanaka M, Nakashima K, et al. Expression of ovarian prolactin receptor in relation to hormonal changes during induction of ovulation in the rat. Gynecol Obstet Invest. 2001;52(2):132-8.

12. Gao J, Lambert RW, Wickham LA, Banting G, Sullivan DA. Androgen control of secretory component mRNA levels in the rat lacrimal gland. J Steroid Biochem Mol Biol. 1995;52(3):239-49.

13. McClellan KA, Robertson FG, Kindblom J, Wennbo $\mathrm{H}$, Tornell J, Bouchard B, et al. Investigation of the role of prolactin in the development and function of the lacrimal and harderian glands using genetically modified mice. Invest Ophthalmol Vis Sci. 2001;42(1):23-30.

14. Payne AP. The harderian gland: a tercentennial review. J Anat. 1994;185(Pt 1):1-49.

15. Panzan MQ, Motta ELA, Haapalainen EF, Soares Jr JM, Nunes MG, Simões RS, et al. Metaclopramideinduced hyperprolactinemia caused marked decline in pinopods and pregnancy rates in mice. Gynecol Endocrinol. 2002;16(1 Suppl):136.

16. Schechter J, Carey J, Wallace M, Wood R. Distribution of growth factors and immune cells are altered in the lacrimal gland during pregnancy and lactation. Exp Eye Res. 2000;71(2):129-42.

17.El Miedany YM, Ahmed I, Moustafa H, El Baddini M. Hyperprolactinemia in Sjogren's syndrome: a patient subset or a disease manifestation? Joint Bone Spine. 2004;71(3):203-8. 